\title{
Assessment of the Reliability and Validity of PLSI in a Turkish Higher Education Institution
}

\author{
Çiğdem Suzan Çardak \\ Anadolu University, Turkey \\ csbelikusakli@anadolu.edu.tr
}

\author{
Meral Güven \\ Anadolu University, Turkey \\ mguven@anadolu.edu.tr
}

\begin{abstract}
Learning style is a significant concept particularly in higher education since it both helps learners plan their learning processes appropriately and guides instructors to design their instructional practices accordingly. Paragon Learning Style Inventory (PLSI) was developed through resorting to Jung's Theory of Psychological Types to assess learning style characteristics, and has been used in higher education successfully. The current study aimed to assess the reliability and validity of the 52-item adult version of the inventory in a Turkish higher education institution. Followed by step to assess linguistic equivalence, confirmatory factor analysis with 855 participants to validate the factor structure and reliability studies were conducted. Findings revealed that the fourdimensional inventory did not fit to the data collected in Turkey. Even though the linguistic equivalence and test-retest reliability were retained, the internal consistency of the inventory was relatively low. Thus, an alternative three-dimensional and 25-item model was proposed, which revealed acceptable or ideal fit indices. Therefore, it was concluded that there is a need for further studies to enhance the inventory and adapt it to the Turkish culture.
\end{abstract}

Keywords: Learning style, Paragon Learning Style Inventory, confirmatory factor analysis, scale adaptation. 


\section{Introduction}

Since the very beginning of $20^{\text {th }}$ century, scientists have been making intense efforts to make sense of how people learn and as a result many learning concepts have been coined and investigated. Among these concepts, the concept of learning styles has gained prominence in recent years as it is directly related to learning at school and life-long learning. As a result, great amount of research has focused on its meaning and effects on learning process.

As is the case for all the concepts related to learning, it is not possible to explain the concept of learning style through a simple definition. Kolb (1984) having important works on the matter defines learning style as ways preferred by an individual during the process of receiving and processing information. In a similar manner, Mariani (1996) defines learner's approach to learning as a permanent way followed by an individual while carrying out perception and responding activities for learning purposes. Woolfolk (1998) on the other hand defines it as individual approach to learning and studying. Without doubt, there are many more definitions in the literature. One of the basic concepts related to learning, learning style can be defined briefly as the learningoriented characteristics of an individual (Güven, 2004). In addition to this, learning styles vary from one individual to another, they allow gaining insights into the personality of a person, they are inherent characteristics, they may vary depending on age, gender and culture and they have cognitive, affective and environmental dimensions (Kolb, 1984; Dunn and Dunn, 1986; Keefe, 1990; Güven, 2004).

It is of great importance for an individual to acquire continuously increasing and changing information without resorting to help of any other people. Hence, an individual knowledgeable about learning styles can make effective use of them and as a result can be successful (Biggs, 2001). 
Moreover, being aware of one's own learning style may help him/her to solve the problems encountered and accordingly to improve self-respect.

It can be argued that on the basis of many learning style models and assessment tools lays Jung's Theory of Psychological Types. Saban (2002) states that Jung's theory provides a conceptual framework to understand learning styles of students. Within this theory, there are primarily two types emphasized being extrovert and introvert (Jung, 1971). While introvert people derive their energy from their inner world rather than external world, extraverts derive their energy mostly from the outside world (Feist, 1990).

Though Jung (1971) defined extraversion and introversion as two basic attitudes, he also stated that people are not only individuated depending on these two attitudes but also their psychological functions as thinking, feeling, sensation and intuition. These functions account for how they collect information and make decisions related to this information (Silver and Hanson, 1996). In other words, the functions accounting for the differences among people are based on two basic cognitive activities being perception and judgment; while perception is realized through sensation and intuition, judgment is realized through thinking and feeling (Silver et al., 2000). In short, Psychological Type Theory is argued to be describing the ways preferred by the individual during adjustment process to a situation encountered to perceive and judge the information exposed to (Bargar and Hoover, 1984).

Based on Jung's theory, Myers-Briggs Type Indicator (MBTI) is used to determine personality types. It is argued that MBTI has made a great contribution to the understanding of Jung's Theory of Psychological Types and to its use in practice (Ekici, 2003; Silver et al. 2000). In addition to this, it is pointed out that there is no evidence showing that MBTI determines or assesses learning styles in the literature (Markham, 2004). However, it is possible to claim that many researchers 
have been affected by Jung's Psychological Types as well as MBTI in developing learning style models and assessment tools. McCarthy, Butler, Gregorc, Silver and Hanson, Mamchur, Keirsley and Bates, Kolb, Felder and Silverman, Shindler are believed to be among the authors affected by Jung's theory and MBTI (Keirsey and Bates, 1984; Felder and Silverman, 1988; Cranton and Knoop, 1995; Silver and Hanson, 1996; Silver et al. 2000; Güven, 2004; Markham, 2004; Shindler and Yang, 2004a). One of the learning style assessment tools developed based on Jung's theory and MBTI, Paragon Learning Style Inventory, has been widely used throughout the world; yet, it has not been adapted to Turkish; hence, the present study aims to deal with this issue.

\section{Paragon Learning Style Inventory}

Paragon Learning Style Inventory (PLSI) based on Jung's theory and MBTI was developed by Dr. Shindler in 1992 to assess learning styles. PLSI is a 52-item assessment tool providing reliable assessments in relation to Jungian psychological types and making individual scoring possible. This learning style inventory has student and adult versions. PLSI used by schools, organizations and individuals all over the world, was last updated in 2003 and this last version includes 52 items (Shindler and Yang, 2004a).

48-item student version of PLSI is freely available in electronic environment. 52-item adult and student versions can be obtained at request. Both 48-item and 52-item inventories assess Jungian psychological types as four dimensions. These are; extrovert/introvert, sensate/intuitive, feeler/thinker and judger/perceiver and learning characteristics in each dimension represent two extremes. Shindler and Yang (2004b) state that though an individual may possess both of the characteristics in each dimension, she/he has a greater tendency towards one of them. When the tendencies for each dimension are considered together, there are 16 combinations emerging and 
accordingly 16 different learning styles. For instance, extravert-intuitive-thinker-perceiver learning style explains the learning characteristics of an individual having all these tendencies. In PLSI, there are 13 items for each of the four sub-dimensions. There are two options for each item as ' $a$ ' and ' $b$ ' and the respondent should choose one of these options. After the completion of the test, the respondent can calculate his/her score by using 'PLSI Score Sheet' (Shindler and Yang, 2004c). To do so, the numbers of the selected ' $a$ ' and ' $b$ ' options should be calculated separately for each dimension. The option with higher number indicates that the person displays the personality characteristic shown in the form for the related dimension. In this way, one preference is determined for each dimension and when the resulting four dimensions are bought together, the learning style of the person is found. Through PLSI, the learning style of a person can easily be determined without needing the help of an expert, which is an important advantage of PLSI. Varughese and Fehring (2009) stated that to assess their students learning styles they preferred this instrument as it is easy to understand and enables scoring individually.

PLSI viewed as a reliable and valid instrument in determining learners' learning styles and cognitive preferences (Overbaugh and Lin, 2006; Shabani, 2012) is particularly applied to conspicuously students of higher education (e.g. Tasker et al. 2003; Yeung et al. 2005; Overbaugh and Lin, 2006; Varughese and Fehring, 2009; Sutherland and Ekker, 2011; Shabani, 2012). In this respect, adaptation of 52-item adult-oriented PLSI, which could be used at higher education level, into Turkish was seen as an important need. Based on this necessity, the present study aims to carry out works required to adapt PLSI into Turkish and to investigate the reliability and validity of the adapted version. It is hoped that the results obtained through this study will help researchers working on learning styles and inventories. 


\section{Method}

\section{Participants of the Study}

The participants of the study are $10131^{\text {st }}, 2^{\text {nd }}, 3^{\text {rd }}$ and $4^{\text {th }}$-year students from the faculties of education, pharmacy, science, engineering-architecture, fine arts, literature, communications sciences, law, economics and administrative sciences of Anadolu University in 2008-2009 academic year. Purposive sampling type (Balc1, 2001) was conducted to decide on the sample and students of each previously indicated departments of the university were represented in the sample.

\section{Procedure}

The procedure given below was followed for the adaptation study:

1. The researchers individually translated the inventory into Turkish. Then, two researchers came together and agreed on a common translation.

2. The Turkish draft of the inventory was submitted to three foreign language experts together with the original English version and their opinions were sought. The three experts presented their opinions in the written format to the researchers. Moreover, face-to-face interviews were conducted with two of the experts and discussions were carried out on how to adapt the items in the inventory into Turkish culture.

3. The Turkish draft developed based on the opinions of foreign language experts was presented to an expert on Turkish language.

4. Based on the feedbacks of the Turkish language expert, it was revised and then it was presented to another expert for reverse translation. The items of reverse translation and those of the original inventory were put into semantic comparison.

5. Following the reverse translation work, Turkish draft of PLSI was submitted to the scrutiny of 30 academicians aged 25-40. The academicians were asked to respond the inventory 
items and put ticks next to the items not clearly understood and write their suggestions, if there are any. The inventories responded by 20 academicians were analysed and the items were revised considering the original inventory.

6. For piloting, the Turkish version of PLSI was administered to $1671^{\text {st }}, 2^{\text {nd }}, 3^{\text {rd }}$ and $4^{\text {th }}$-year students from different departments of the Faculty of Education of Anadolu University. The piloting was conducted to see whether there were any problems that may emerge during the application process and the internal consistency value was enough to administer the inventory to the large sample. The piloting was conducted by the researchers and they observed the participants throughout the piloting. The reliability of the inventory in terms of internal consistency was found to be at an acceptable level (KR-20=.67) and no further correction was made on the draft inventory before its administration to the large sample.

7. Following the piloting, linguistic equivalence work was performed. The linguistic equivalence work was participated by 35 third-year students from the department of ELT of the Faculty of Education at Anadolu University. First, the students were administered the original inventory and three weeks later, the same students were administered the Turkish version of the inventory developed within the present study.

8. The Turkish version of PLSI was administered to randomly-selected undergraduate students of Anadolu University and after the elimination of those leaving five or more items not-responded or those marking both of the options for an item, there were 1013 inventories left for the analysis.

9. In order to determine the construct validity of Turkish PLSI, confirmatory factor analysis was conducted with 855 fully completed inventories. 
10. In order to establish the reliability of Turkish PLSI, internal consistency and reliability in means of stability were investigated. KR-20 value was calculated and in terms of stability, test-retest method was used. In this regard, the Turkish inventory was administered to 58 third-year students of social studies from the Department of Primary Education at Anadolu University twice at a four week-interval.

\section{Data Analysis}

The analysis concerning the linguistic equivalence was carried out through 'Wilcoxon Signed Rank Test for Paired Samples' in SPSS 15.0 program package to determine the linguistic equivalence for the four sub-dimensions of PLSI.

Confirmatory Factor Analysis (CFA) was performed through Lisrel 8.7 program package; hence, as the data type is categorical, correlation and asymptotic covariance matrices were formed and they were used together with 'Weighted Least Squares' method as proposed by Şimşek (2007, p. 201).

In the evaluation of the models tested during the process of CFA, $t$-values related to observed variables and variance (error) that could not be explained in the observed variables and goodnessof-fit indices were examined respectively. In this respect, firstly, the variables having a $t$ value lower than 1.96 at the significance level of .05 were determined and discarded from the model (Çokluk et al. 2010). Then, the error variances related to the observed variables were examined. Starting from the highest error value, the observed variables having high error values were discarded from the model one by one. Finally, fit indices for the model where all the t-values are significant and the error variances related to the observed variables were found to be lower than .94 were interpreted. 
It is reported that Lisrel 8 output file presents all the fit indices discussed in the literature (Jöreskog and Sörbom, 1996). However, it can be told that reporting of all the indices is not suitable in practice. In the present study, fit indices which can be regarded as frequently used fit indices as Goodness-of-fit Index (GFI), Adjusted Goodness-of-fit Index (AGFI), Comparative Fit Index (CFI)), Root Mean Square Residual (RMR), Root Mean Square Error of Approximation (RMSEA) were reported. In addition to these, the ratio of Chi-square value to degree of freedom was also taken into consideration.

In order to determine the internal consistency of PLSI, for each sub-dimension and for the whole inventory, KR-20 value was calculated and interpreted because of the dichotomous response structure of the PLSI. In the determination of the test-retest stability of the four sub-dimensions of the inventory, the non-parametric 'Wilcoxon Signed Rank Test for Paired Samples' was conducted instead of 'Paired-Samples T-Test' because the latter requires normal distribution (Büyüköztürk, 2011).

\section{Findings}

\section{Findings for Linguistic Equivalence}

The results of the 'Wilcoxon Signed Rank Test for Paired Samples' conducted to determine the linguistic equivalence of PLSI are presented in Table 1.

Table 1

The results of 'Wilcoxon Signed Rank Test for Paired Samples'

\begin{tabular}{lllll}
\hline Original-Turkish PLSI & $\begin{array}{c}\text { Introvert } \\
\text { Extrovert }\end{array}$ & $\begin{array}{c}\text { Sensate } \\
\text { Intuitive }\end{array}$ & $\begin{array}{c}\text { Thinker } \\
\text { Feeler }\end{array}$ & $\begin{array}{c}\text { Judger } \\
\text { Perceiver }\end{array}$ \\
\hline $\mathrm{Z}$ &,- 513 & $-1,069$ & $-1,395$ &,- 388 \\
\hline $\begin{array}{l}\text { Asymp. Sig. } \\
\text { (2-tailed) }\end{array}$ &, 608 &, 285 &, 163 &, 698 \\
\hline
\end{tabular}


As can be seen on Table 1, there is no significant difference between the scores taken from original English inventory and Turkish inventory for each of the four sub-dimensions (for introvert/extrovert sub-dimension $\mathrm{z}=-, 513, \mathrm{p}>.05$; for sensate/intuitive sub-dimension $\mathrm{z}=-1,069$, $\mathrm{p}>.05$; for thinker/feeler sub-dimension $\mathrm{z}=-1,395, \mathrm{p}>.05$; and judger/perceiver sub-dimension $\mathrm{z}=-$ 0,388, $\mathrm{p}>.05)$. In addition to rigorous translation efforts, this finding can be considered as important evidence showing that Turkish PLSI has a linguistic equivalence.

\section{Findings of Confirmatory Factor Analysis}

To test whether the well-defined four dimensional and 52-item model of PLSI was confirmed by the data obtained through the current study or not, confirmatory factor analysis was conducted (Şimşek, 2007). The widely used original structure of the PLSI was presented in Table 2.

Table 2

The Structure of the 52-item PLSI

\begin{tabular}{lll}
\hline Sub-Dimensions & Item Numbers & Total Item \\
\hline Introvert-Extrovert (I-E) & $1-5-9-13-17-21-25-29-33-37-41-$ & 13 \\
& $45-49$ & \\
\hline Sensate - Intuitive (S-I) & $2-6-10-14-18-22-26-30-34-38-$ & 13 \\
& $42-46-50$ & \\
\hline Thinker- Feeler (T-F) & $3-7-11-15-19-23-27-31-35-39-43-$ & 13 \\
& $47-51$ & 13 \\
\hline Judger - Perceiver (J-P) & $4-8-12-16-20-24-28-32-36-40-$ & \\
\hline & $44-48-52$ & 52 \\
\hline
\end{tabular}

For the operations performed during the process of confirmatory factor analysis conducted to test the conformity of the showed model of PLSI on Table 2 to Turkish Culture, criteria explained in the data analysis section were taken into consideration. Moreover, the observed variables in the model will be referred as 'Item' thereafter in the present study. 


\section{The first operation}

The original 4-factor 52-item Model-1 (52 Items) was tested through 'Weighted Least Squares' method and goodness-of-fit indices and path diagram were obtained. However, when the output file was analyzed in detail, 'not positive definite' warning was seen. Moreover, it was observed that with regards to the correlation matrix of latent variables, the state in Table 3 holds true.

Table 3

Correlation matrix of latent variables

\begin{tabular}{lllll}
\hline & I-E & S-I & T-F & J-P \\
\hline I-E & 1.00 & & & \\
\hline S-I & -0.19 & 1.00 & & \\
\hline T-F & 0.85 & -0.07 & 1.00 & 1.00 \\
\hline J-P & -0.22 & 0.99 & -0.03 & \\
\hline
\end{tabular}

As can be seen in Table 3, a correlation with the value of .85 was found between the introvertextrovert (I-E) latent variable and thinker-feeler (T-F) variable and a correlation value of .99 was found between sensate-intuitive (S-I) latent variable and judger-perceiver (J-P) variable. In this regard, especially the value of correlation between sensate-intuitive (S-I) and judger-perceiver (JP) latent variables was very high and these two dimensions were not independent from each other. It was assumed that this might have led to warning 'not positive definite' seen in the output file.

\section{The second operation}

The S-I and J-P latent variables exhibiting a correlation value of .99 were combined and defined as a single latent variable (S-I/J-P). This new 3-dimensional 52-item Model-2(52 Items) was tested through again 'Weighted Least Squares' method. When the output file was analyzed, it was seen that there is no 'not positive definite' warning in the second operation. As a result of this, confirmatory factor analysis works were carried on Model-2 with 3 latent variables. In this process, firstly t-values were examined. If any relations defined in the model were found to be not 
statistically meaningful as a result of the analysis, excluding these relations with no regard to fit indices is recommended (Şimşek, 2007). Thus, the relations related to Item 8 , Item 11, Item 22 , Item 38 and Item 50 were discarded from the model because of having insignificant t-values.

\section{The third operation}

During the third operation for CFA with the remaining 47 items, Model-2(47 Item) was tested. In this model, as all the t-values related to the items were found to be significant, error variances of the items were analyzed. Through the analysis conducted in relation to error variances, the items having the highest error values were determined and starting from the item with the highest error variance, the items were excluded from the model one by one and in each resulting state, the model was retested. In each test, warnings in the output file, t-values and error variances were respectively analyzed. As the items were discarded from the model one by one depending on error variance, 22 further operations were realized after the third operation.

\section{The twenty fifth operation}

As a final operation, three-factor Model-2 (25 Item) was tested with the remaining 25 items. Because there was no warning message in the output file of the 25 -item model and all the t-values were significant, the error variances of the items were analyzed; and two items with the highest error variance of .93 were found and though error variance value of .93 was considered to be high, these two items were kept within the model, as all the t-values in the model were significant and content validity was taken into consideration. In Table 4, some goodness-of-fit indices obtained during the first, second, third and twenty fifth operations are presented.

Table 4

Goodness-of-fit indices regarding the model of PLSI

\begin{tabular}{lccccccccc}
\hline \multicolumn{1}{c}{ Operations } & $\mathbf{x}^{\mathbf{2}}$ & $\mathbf{d f}$ & $\mathbf{p}$ & $\mathbf{x}^{2} / \mathbf{d f}$ & GFI & AGFI & CFI & RMR & RMSEA \\
\hline $\begin{array}{l}\text { Operation-1: } \\
\begin{array}{l}\text { Model-1 } \\
\text { (52 Item) }\end{array}\end{array}$ & 2793.67 & 1268 & .0000 & 2,2032 & .94 & .94 & .54 & .061 & .038 \\
\hline
\end{tabular}




\begin{tabular}{llllllllll}
\hline $\begin{array}{l}\text { Operation-2: } \\
\begin{array}{l}\text { Model-2 } \\
\text { (52 Item) }\end{array}\end{array}$ & 2797.28 & 1271 & .0000 & 2,2008 & .94 & .94 & .54 & .061 & .037 \\
\hline $\begin{array}{l}\text { Operation-3: } \\
\begin{array}{l}\text { Model-2 } \\
\text { (47 Item) }\end{array}\end{array}$ & 2220.82 & 1031 & .0000 & 2,1540 & .95 & .94 & .59 & .057 & .037 \\
\hline $\begin{array}{l}\text { Operation-25: } \\
\begin{array}{l}\text { Model-2 } \\
(25 \text { Item })\end{array}\end{array}$ & 620.49 & 272 & .0000 & 2,2812 & .97 & .97 & .80 & .052 & .039 \\
\hline
\end{tabular}

Though Chi-square values are expected to be insignificant in confirmatory factor analysis, they are usually found to be high in applications and it is quite normal particularly in case of large samples (Şimşek, 2007; Çokluk et al, 2010). In all of the four operations shown in Table 4, Chisquare values were found to be significant; hence, the ratio of Chi-square value to the degree of freedom was taken into consideration. It is reported that the ratio of Chi-square to degree of freedom lower than five indicates an acceptable model and a ratio lower than two indicates a good model (Şimşek, 2007). However, it is stated that in larger samples, Chi-square value is also higher and in this respect, the ratio of Chi-square value to degree of freedom is expected to be bigger (Mueller, 1996). According to Kline (2005), the ratio lower than three in larger samples indicates a perfect fit (Cited in Çokluk et al., 2010). Given that the sample used in the present study is a large sample, it can be argued that the ratio of Chi-square value to degree of freedom (2.28 for Model-2(25 Item) $)$ represents a perfect fit.

In the literature it is reported that the GFI, AGFI and CFI goodness-of-fit indices higher than .90 indicate acceptable fit value and values bigger than .95 are indication of a good fit value (Şimşek, 2007; Yılmaz and Çelik, 2009). As can be seen in Table 4, with the further operations, the GFI, AGFI and CFI values increased in the present study and for Model-2 (25 Item) representing the $25^{\text {th }}$ operation, these values were as follows: $\mathrm{GFI}=.97, \mathrm{AGFI}=.97, \mathrm{CFI}=.80$. While GFI and AGFI values were higher than .95 , CFI value remained under .90 though it continuously increased. Yet, 
West, Finc and Curan (1995), stated that when there is a normal distribution, CFI value is used to make quite reliable predictions (Cited in Şimşek, 2007). In this respect, according to GFI and AGFI values, it can be argued that Model-2 25 Item) tested in the $25^{\text {th }}$ operation exhibits a good fit.

Other goodness-of-fit indices, RMR and RMSEA, are reported to show a good fit if they are lower than .05 (Şimşek, 2007; Y1lmaz and Çelik, 2009). As presented in Table 4, RMR value decreased after the first operation, in Model-2(25 Item), RMR gained the value of .052 . RMSEA, on the other hand, retained the value of .039 in general. RMR value around .05 and RMSEA value lower than .05 indicate a good fit especially for Model-2(25 Item).

According to the goodness-of-fit indices presented in Table 4 , Model-2(25 Item) tested in the $25^{\text {th }}$ operation was observed to exhibit the best fit to the data at hand. In this respect, it can be argued that three-factor 25-item model of PLSI shows best fit to the data obtained in this study. 'Path Diagram' related to Model-2 $(25$ Item) is presented in Figure 1.

In Fig.1, the correlation among the sub-dimensions of 25-item PLSI is also shown. The correlation between introvert-extrovert (I-E) and thinker-feeler (T-F) dimensions reached .90 in the 25th operation. As it is seen on Figure 1, the T-F dimension of the model was represented by only two items. Thus the content validity of the T-F dimension had become weaken seriously. 


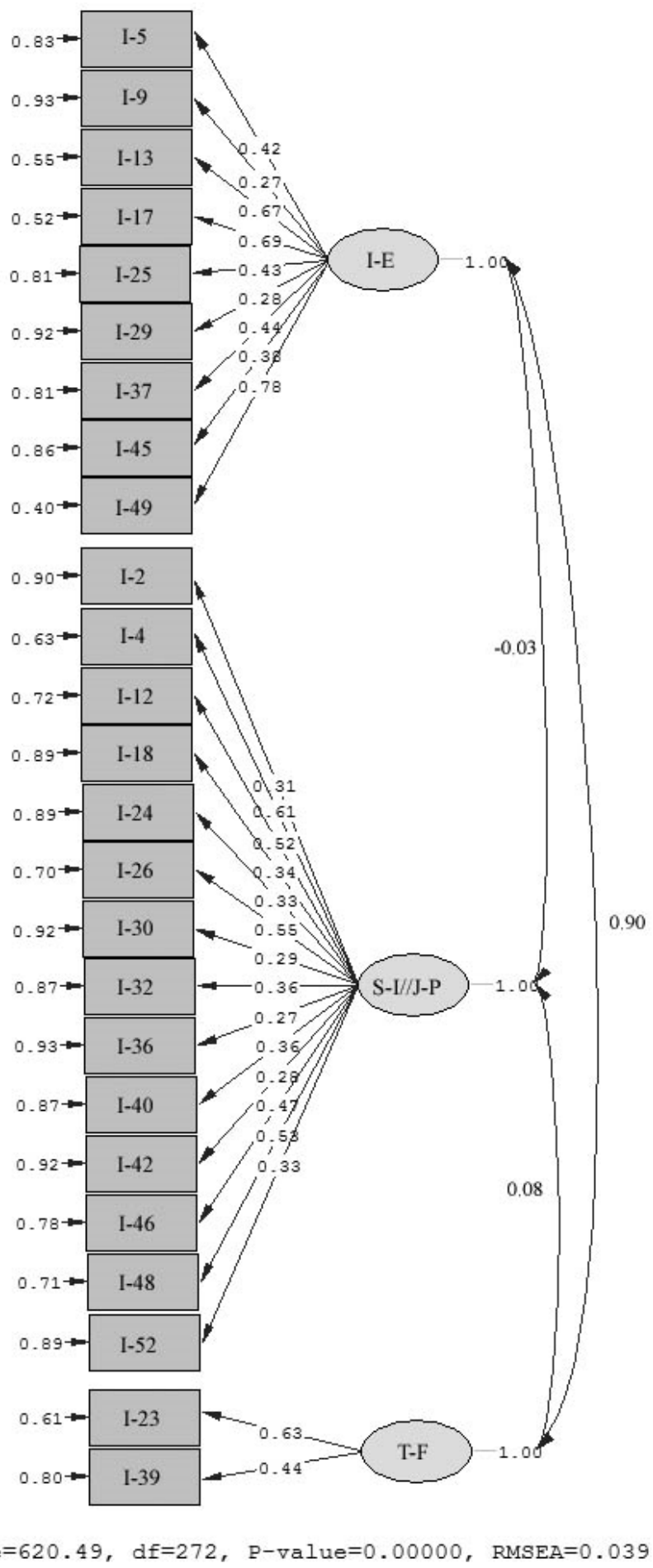

Figure 1. Path diagram of 25-item PLSI with three sub-dimensions 


\section{Reliability Works}

\section{Internal Consistency}

KR-20 value of PLSI was found to be .62. The reliability values of the sub-dimensions ranged from .43 to .67 (.67 for extravert/introvert sub-dimension, .43 for sensate/intuitive subdimension, .44 for thinker-feeler sub-dimension, and .48 for judger-perceiver). When the sensateintuitive and judger-perceiver sub-dimensions showing a high correlation were combined, internal consistency value increased to .62. For the final model of PLSI which was obtained through the CFA study, reliability values were calculated again: Internal consistency value of the PLSI increased to .70 while the reliability values of the sub-dimensions of extravert/introvert, sensateintuitive/judger-perceiver and thinker-feeler were calculated as .70, .69 and .43 respectively.

\section{Test-retest stability}

Test-retest test technique was followed to determine the reliability of Turkish Paragon Learning Style Inventory in terms of stability. 'Wilcoxon Signed Rank Test for Paired Samples' was conducted for test-retest test reliability and the results for each sub-dimension are given in Table 5.

Table 5

The results of 'Wilcoxon Signed Rank Test for Paired Samples'

\begin{tabular}{lcccc}
\hline Test-Retest & $\begin{array}{c}\text { Extrovert } \\
\text { Introvert }\end{array}$ & $\begin{array}{c}\text { Sensate } \\
\text { Intuitive }\end{array}$ & $\begin{array}{c}\text { Thinker } \\
\text { Feeler }\end{array}$ & $\begin{array}{c}\text { Judger } \\
\text { Perceiver }\end{array}$ \\
\hline $\mathrm{Z}$ &,- 133 &,- 910 & $-1,324$ & $-1,286$ \\
\hline $\begin{array}{l}\text { Asymp. Sig. } \\
\text { (2-tailed) }\end{array}$ &, 894 &, 363 &, 186 &, 198 \\
\hline
\end{tabular}

As can be seen in Table 5, no significant difference was found between the four sub-dimensions of the two scale values (for extravert/introvert sub-dimension $z=-, 133, p>.05$; for sensate/intuitive sub-dimension $\mathrm{z}=-, 910, \mathrm{p}>.05$; for thinker/feeler sub-dimension $\mathrm{z}=-1,324, \mathrm{p}>.05$; for 
judger/perceiver sub-dimension $\mathrm{z}=-1,286, \mathrm{p}>.05$ ). This finding is regarded as an evidence for the reliability of Turkish PLSI in terms of stability.

\section{Discussion and Conclusion}

Confirmatory factor analysis is defined as an analysis process where a structure whose borders are described is viewed as a model and in which whether this model has been confirmed or not is investigated (Çokluk et al., 2010). Evaluation of the general fit of the model at hand can be defined as the determination of the extent to which the model complies with the experimental data at hand (Diamantopoulos and Siguaw, 2000). In the present study, the fit of the structural model of PLSI whose structure has been determined in advance to the data collected within the framework of the present study in Turkey was evaluated through confirmatory factor analysis. Therefore, directly confirmatory factor analysis was conducted to determine the construct validity in this adaptation work of PLSI into Turkish. Çokluk et al. (2010) state that it is possible to directly conduct confirmatory factor analysis without first conducting explanatory factor analysis in inter-cultural adaptation studies.

Throughout the process of confirmatory factor analysis carried out for the construct validity of PLSI, it was observed that sensate-intuitive and judger-perceiver sub-dimensions of the inventory exhibited a high level of correlation. Shindler and Yang (2004a) stated that the PLSI consists of four dimensions and these dimensions are nearly independent of each other and there is a slight correlation only between sensate-intuitive sub-dimension and judger-perceiver sub-dimension. However, the slight correlation pointed out between sensate-intuitive and judger-perceiver subdimensions by Shindler and Yang was found to be quite high in this present study (.99). In this respect, it can be argued that the learning styles of the students participating in this study could not be discriminated according to these two sub-dimensions. In a similar manner, during the first 
operation, a correlation value of .85 was found between extravert-introvert sub-dimension and thinker-feeler sub-dimension. During the process of confirmatory factor analysis, only the two subdimensions exhibiting a correlation at the level of .99 were combined and the study went on with three-dimensional model. However, in the light of the findings of the current study, in the further studies, extravert-introvert and thinker-feeler sub-dimensions of the model require critical review because of the considerable correlation between them and the weak content validity of the thinkerfeeler sub-dimension.

As a result of the confirmatory factor analysis performed through 25-item model with three subdimensions was obtained and the goodness-of-fit values of this model exhibited data-model fit. Mueller (1996) reported that the data-model fit found in an application indicate that there is not enough evidence to refute the model. Thus according to the results of the CFA, it is not possible to state that the 25 -item model with three sub-dimensions does not fit the observed data of the study. For further research it could be suggested that 25-item PLSI with three sub-dimension should be administered to a new sample in Turkey and the data to be collected can be exposed to explanatory factor analysis to see whether the three-dimensional structure re-emerge again. Yet, while conducting the explanatory factor analysis, the type of the data should be considered. Moreover, giving a new name to the combined two sub-dimensions (sensate-intuitive and judger-perceiver) and discussing the meaningfulness and the function of the new combined dimension among the others regarding the learning styles could be suitable. While deciding this new name, four learning style preference of two sub-dimensions should be considered by the researchers from the fields of education psychology and learning styles so that an appropriate name could be found.

In addition to validity works of PLSI, reliability of the inventory should be taken into consideration. As a result of the test-retest performed in the present study, it can be argued that PLSI has stability. 
However, it was observed that there are some problems in the sub-dimensions in terms of internal consistency. Except for extravert-introvert sub-dimension, the internal consistency values for the other three sub-dimensions are lower than .50 and this indicates that there is a need to be cautious about the results obtained from these three sub-dimensions. Yet, throughout the confirmatory factor analysis study, it was observed that there is a need to combine sensate-intuitive and judgerperceiver sub-dimensions. Hence, when PLSI was considered to be three-dimensional, the reliability of extravert-introvert sub-dimension was found to be .67 , the reliability of the combined sensate-intuitive and judger-feeler sub-dimension was found to be .62 . The reliability of the third sub-dimension, thinker-feeler, on the other hand was found to be .44 . The last one is a quite low value. In addition, the three-dimensional 25-item PLSI which was obtained through the CFA study gave much more good results in means of reliability. However, the reliability values of the final model of the inventory might be investigated in further studies with new empirical data.

Some other similar studies conducted in Turkey have also revealed similar low reliability values. For instance, Arslan (2003) used four-dimensional Felder-Solomon Index of Learning Styles having a structure similar to that of PLSI in her study and reported the following reliability values for the sub-dimensions; $.49, .55, .53$ and .29 . The same index was adapted again to Turkish by Samanc1 and Keskin (2007) and they found these reliability values for the sub-dimensions of the index; $.43, .54, .59$ and .32. Index of Learning Styles offers only 'a' and 'b' options like PLSI. In this respect, obligation of selecting one of the two options imposed by PLSI items may indicate a difficulty experienced by respondents to select items adequately representing their learning characteristics. In this regard, for further research, it can be suggested to rearrange and turn PLSI items into Likert-type items. 
In another study, Y1lmaz-Tuzun and Topcu (2008) reported that the reliability values of the factors of epistemology scale adapted to Turkish range from .20 to .60. The reason for these low values was claimed to stem from translation problems and the same reason may hold true for the present study. Though rather than verbatim translation, semantic translation was tried to be achieved in the present study, it can be argued that the participants of the present study may not have found the inventory items developed for people from a different culture suitable for themselves. The items of the sub-dimensions found to have a reliability value lower than .50 in the present study can be recommended to be revised and new items suitable for Turkish culture should replace them.

The findings of the present study cannot be generalized to all the undergraduate students of Turkish Higher Education System. The findings are limited to the undergraduate students from Anadolu University; hence, the study can be repeated by administering PLSI to other universities.

As a conclusion, the present study conducted to adapt PLSI into Turkish and determine whether its structure is suitable for Turkish culture revealed that three-dimensional 25-item model instead of four-dimensional 52-item model exhibits a better fit to the data of the present study. Moreover, as the reliability value of the thinker-feeler sub-dimension is lower than .50 and the reliability values of extravert-introvert sub-dimension and other combined dimensions are lower than .70, the scores regarding the learning styles of the individuals retrieved from the Turkish PLSI are open to questioning. Shindler and Yang (2004a) argue that all the inventories aiming to elicit information related to behaviors or characteristics and based on self-reporting never provide perfect information and though PLSI is good at determining the correct type in relation to learning styles, it is not perfect. In the present study, PLSI did not provide good results in Turkish culture, and there is a need for further research to reliably and validly evaluate learning styles by using PLSI. 


\section{Acknowledgements}

The authors would like to thank to Prof.Dr. John Schindler for his kindly permission for Turkish adaptation study of PLSI and Assist.Prof.Dr. Rıdvan Tunçel for his great effort during the translation process of PLSI into Turkish.

\section{References}

Arslan, B. (2003). A Descriptive Study of Learning Style Preferences of the Engineering Students at METU. Unpublished Master's Thesis, Middle East Technical University.

Balc1, A. (2001). Sosyal Bilimlerde Araştırma: Yöntem, Teknik ve Illkeler.[Research in Social Sciences: Method, Technique and Principles]. Üçüncü Basım. Ankara: Pegem A Yayıncılık.

Bargar, R. R. \& Hoover, R. L. (1984). Psychological Type and the Matching of Cognitive Styles. Theory into Practice, 23(1), 56-63.

Biggs, J. (2001). Enhancing Learning: A Matter of Style or Approach. In R. J. Sternberg \& L. - F. Zhang (Eds.), Perspectives on Thinking, Learning and Cognitive Styles (pp. 73-102). Mahwah: Lawrance Erlbaum Associates.

Büyüköztürk, Ş. (2011). Sosyal Bilimler İçin Veri Analizi El Kitabı. [Data Analysis Handbook for Social Sciences]. 14. Basım. Ankara: Pegem A Yayıncılık.

Cranton, P. \& Knoop, R. (1995). Assessing Jung's Psychological Types: The PET Type Check. Genetic, Social \& General Psychology Monographs, 121 (2), 247-274.

Çokluk, Ö. Şekercioğlu, G. \& Büyüköztürk, Ş. (2010). Sosyal Bilimler İçin Çok Değişkenli İstatistik: SPSS ve LISREL Uygulamalarl [Multi Variable Statistics for Social Sciences: SPSS and LISREL Applications]. Ankara: Pegem Akademi.

Diamantopoulos, A. \& Siguaw J. A. (2000). Introducing Lisrel. London: SAGE Publications Ltd. 
Dunn, K. \& R. Dunn. (1986). The Look of Learning Styles. Early Years. 8, 46-52.

Ekici, G. (2003). Öğrenme Stiline Dayalı Öğretim ve Biyoloji Dersi Öğretimine Yönelik Ders Planı Örnekleri [Learning Style Based Instruction and Lesson Plans for Course of Biology]. Ankara: Gazi Kitapevi.

Feist, J. (1990). Theories of Personality (2 ${ }^{\text {nd }}$ ed.). USA: Holt, Rinehart and Winston, Inc..

Felder, R. \& Silverman, L. (1988). Learning and Teaching Styles in Engineering Education. Engr.Education, 78(7), 674-681.

Güven, M. (2004). Öğrenme Stilleri ile Öğrenme Stratejileri Arasındaki İlişki [The Relationship Between Learning Styles and Learning Strategies]. Eskişehir: Anadolu Üniversitesi.

Jöreskog, K. \& Sörbom, D. (1996). Lisrel 8: User's Reference Guide. Chicago: Scientific Software International, Inc.

Jung, C. G. (1971). Psycholojical Types: The Collected Works of C. G. Jung. S. H. Read, M. Fordham, G. Adler, W. Mcguire (Eds.). Princeton University Press.

Keefe, J. W. (1990). Learning Style Profile Handbook: Volume II, Developing Cognitive Skills. Reston: National Association of Secondary School Principals.

Keirsey, D. \& Bates, M. (1984). Please Understand Me: Character \& Temperament Types. Prometheus Nemesis Book Company.

Kolb, D. (1984). Experiential Learning-Experience as The Source of Learning and Development. New Jersey: Prentice Hall.

Mariani, L. (1996). Investigating Learning Styles. Journal of Tesol. 21(2), 1-13.

Marhkham, S. (2004). Learning Styles Measurement: A Cause for Concern. Technical Report: Computing Educational Research Group. http://cerg.csse.monash.edu.au/ techreps/learning_styles_review.pdf Accessed 2 February 2007. 
Mueller, R. O. (1996). Basic Principles of Structural Equation Modeling: An Introduction to LISREL and EQS. USA: Springer.

Overbaugh, R. C. \& Lin, S. Y. (2006). Student Characteristics, Sense of Community, and Cognitive Achievement in Web-based and Lab-based Learning Environments. Journal of Research on Technology in Education, 39(2), 205-223.

Saban, A. (2002). Öğretme Öğrenme Süreci: Yeni Teori ve Yaklaşımlar [Teaching Learning Process: New Theories and Approaches]. Ankara: Nobel Yayın Dağıtım, 2002.

Samanc1, N. K. \& Keskin, M. Ö. (2007). Felder-Soloman Öğrenme Stili İndeksi: Türkçe’ye Uyarlanması ve Geçerlik-Güvenirlik Çalışması [Felder-Soloman Index of Learning Styles: Adapting into Turkish and Validity-Reliability Study]. Ahi Evran Üniversitesi Kırşehir Eğitim Fakültesi Dergisi (KEFAD), 8(2), 37-54.

Shabani, M. B. (2012). Different Learning Style Preferences of Male and Female Iranian Nonacademic EFL Learners. English Language Teaching, 5(9), 127-137.

Shindler, J. \&Yang, H. (2004a). About PLSI. Paragon Learning Style Inventory Web site. http://www.calstatela.edu/faculty/jshindl/plsi/plsinfo.htm. Accessed 7 March 2013.

Shindler, J. \& Yang, H. (2004b). Four Dimensions. Paragon Learning Style Inventory Web site. http://www.calstatela.edu/faculty/jshindl/plsi/4dimen.htm. Accessed 7 March 2013.

Shindler, J. \& Yang, H. (2004c). PLSI Score Sheet. Paragon Learning Style Inventory Web site. http://www.calstatela.edu/faculty/jshindl/plsi/forma.htm. Accessed 7 March 2013.

Silver, H. F. \& Hanson, J. R. (1996). Learning Styles \& Strategies. Trenton: Silver Strong\&Associates, Inc..

Silver, H. F., Strong, R. W. \& Perini, M. J. (2000). Integrating Learning Styles and Multible Intelligences. USA: Silver Strong\&Associates, Inc., 2000. 
Sutherland, J. L. \& Ekker, K. (2011). Simulation-Games as a Learning Experience: An Analysis of Learning Style and Attitude. In Ifenthaler, D., Spector, J.M., Kinshuk, Isaias, P. \& Sampson, D.G. (Eds.), Multiple Perspectives on Problem Solving and Learning in the Digital Age. Springer.

Şimşek, Ö. F. (2007). Yapısal Eşitlik Modellemesine Giriş: Temel İlkeler ve LISREL Uygulamaları [Introduction to Structural Equation Modeling: Basic Principles and LISREL Applications]. Ankara: Ekinoks.

Tasker, R., Miller, J., Kemmett, C., \& Bedgood, Jr., D. R. (2003). Analysis of student engagement with online chemistry modules using tracking data. In G.Crisp, D.Thiele, I.Scholten, S.Barker \& J.Baron (Eds.), Interact, Integrate, Impact: Proceedings of the 20th Annual Conference of the Australasian Society for Computers in Learning in Tertiary Education (pp. 505-514). http://cms.ascilite.org.au/conferences/adelaide03/docs/pdf/505.pdf. Accessed 10 December 2012.

Varughese, V. K. \& Fehring, H. (2009). Effects of Students' Approaches to Learning on Performance in Two Pedagogical Environments. International Education Studies, 2(4),1014.

Woolfolk, A. E. (1998). Educational Psychology. Seventh edition. Needham Heights, M. A.: Allyn and Bacon.

Yeung, A., Read, J., \& Schmid, S. (2005). Students' learning styles and academic performance in first year chemistry. In Proceedings of the UniServe Science Blended Learning Symposium (pp. 137-142). $\quad$ AU: Sydney. http://science.uniserve.edu.au/pubs/procs/wshop10/2005Yeung.pdf. Accessed 10 December 2012. 
Yılmaz, V. ve Çelik, H. E. (2009). LISREL ile Yapısal Eşitlik Modellemesi-I: Temel Kavramlar, Uygulamalar, Programlama [Structural Equation Modeling with LISREL - I: Basic Concepts, Applications and Programming]. Ankara: Pegem Akademi.

Yılmaz-Tuzun, O. \& Topçu, M. S. (2008). Relationships among Preservice Science Teachers' Epistemolojical Beliefs, Epistemolojical World Views, and Self-efficacy Beliefs. International Journal of Science Education, 30(1), 65-85. 